Full length article

\title{
Radiolytic synthesis of manganese oxides and their ability to decolorize methylene blue in aqueous solutions
}

\author{
L. Mikac ${ }^{a, b}$, I. Marićc, G. Štefanićc ${ }^{a, b}$, T. Jurkin ${ }^{c}$, M. Ivanda ${ }^{a, b, *}$, M. Gotićc ${ }^{a, b, *}$ \\ ${ }^{a}$ Center of Excellence for Advanced Materials and Sensing Devices, Research Unit New Functional Materials, Ruđer Bošković Institute, Bijenička c.54, Zagreb, Croatia \\ ${ }^{\mathrm{b}}$ Molecular Physics and New Materials Synthesis Laboratory, Ruđer Bošković Institute, Bijenička 54, 10000 Zagreb, Croatia \\ ${ }^{\mathrm{c}}$ Radiation Chemistry and Dosimetry Laboratory, Ruđer Bošković Institute, Bijenička c. 54, Zagreb, Croatia
}

\section{A R T I C L E I N F O}

\section{Keywords:}

Manganese oxides

Gamma-irradiation

DEAE dextran

Methylene blue

\begin{abstract}
A B S T R A C T
In this work, manganese oxide nanoparticles were radiolytically synthesized in the presence or absence of diethylaminoethyl-dextran hydrochloride (DEAE-dextran). Deoxygenated potassium permanganate $\left(\mathrm{KMnO}_{4}\right)$ alkaline aqueous suspensions were used as a precursor. The dose rate was $\sim 32 \mathrm{kGy} \mathrm{h}^{-1}$ and the absorbed doses were 100 and $200 \mathrm{kGy}$. The XRD patterns showed broad peaks indicating the low crystallinity and/or amorphous character of synthesized manganese oxides samples. The radiolytically synthesized samples in the presence of DEAE-dextran contained a mixture of phases, namely $\mathrm{Mn}_{2} \mathrm{O}_{3}, \mathrm{Mn}_{3} \mathrm{O}_{4}$ and an amorphous phase. The samples radiolytically synthesized with no added polymer consist of $\mathrm{K}_{0.27} \mathrm{MnO}_{2} \cdot 0.54 \mathrm{H}_{2} \mathrm{O}$ and $\mathrm{Mn}_{3} \mathrm{O}_{4}$ (hausmannite). The volume average domain size of hausmannite was estimated to $\sim 45 \mathrm{~nm}$ using Scherrer equation and Williamson-Hall plots. The hydrodynamic diameters and zeta potential of the samples were measured. The pore radius distributions and pore volume of the obtained manganese oxides were determined by $\mathrm{N}_{2}$ adsorption-desorption measurements. The synthesized manganese oxide samples were applied for decolorization of methylene blue $(\mathrm{MB})$ aqueous solutions at $\mathrm{pH}=2$. The $\mathrm{MB}$ concentrations in the supernatant solutions were determined through the measurements of the UV-Vis absorbance intensities at a wavelength of $663 \mathrm{~nm}$. The radiolytically synthesized $\mathrm{Mn}_{3} \mathrm{O}_{4} \mathrm{NPs}$ in the absence of DEAE-dextran polymer (zeta potential of $-39.4 \mathrm{mV}$, BET surface area of $234 \mathrm{~m}^{2} \mathrm{~g}^{-1}$ and pore volume of $1.52 \mathrm{~cm}^{3} \mathrm{~g}^{-1}$ ) showed the highest MB decolorization effect.
\end{abstract}

\section{Introduction}

Manganese oxides are very important materials, which are commonly used in a wide range of applications. Due to their excellent electrochemical activity, the manganese oxides $\left(\mathrm{MnO}, \mathrm{MnO}_{2}\right.$, and $\mathrm{Mn}_{3} \mathrm{O}_{4}$ ) are used in the fabrication of sensors, supercapacitors, and rechargeable batteries [1,2]. For instance, hausmannite $\left(\mathrm{Mn}_{3} \mathrm{O}_{4}\right)$ has an application in fuel cells, as an electrochemical material, catalyst, magnetic storage medium etc. [3,4]. In comparison with other oxides, manganese oxides show a low conversion potential, and they are environmentally friendly, which is one of the main reasons for their applications. Manganese oxides are active catalysts for oxidation of methane and $\mathrm{CO}$ and the combustion of organic compounds used in environmental applications [5-7]. Methylene blue (MB) is a synthetic organic dye widely used in textile, paper, and other industries [8-10]. $\mathrm{MB}$ is used to color products and in this process a significant amount of wastewater is generated. MB may cause damage to humans and ecosystems due to its mutagenic and carcinogenic effects [11]. Therefore, the efficient removal of methylene blue and other common dyes from water is crucial in terms of health and environmental concerns. Since the synthetic dyes are generally non-biodegradable in addition to traditional processes for wastewater treatments, like adsorption, biodegradation, chlorination and ozonation, the new methods should be developed [12-14]. Due to these reasons, the radiolytically synthesized manganese oxide NPs were tested for decolorization of MB organic dye.

Manganese oxide nanoparticles (NPs) of various shapes can be synthesized using the hydrothermal method [15-17]. Other commonly used methods are sol-gel synthesis [18,19], wet chemical route [20,21] and pulsed laser deposition [22,23]. Furthermore, the manganese oxide nanostructures have been synthesized starting from potassium permanganate $\left(\mathrm{KMnO}_{4}\right)$ precursor [24]. Bach and co-workers used the reduction of permanganate aqueous solutions $\mathrm{AMnO}_{4}[\mathrm{~A}=\mathrm{Li}, \mathrm{Na}, \mathrm{K}$, $\left.\mathrm{NH}_{4}, \mathrm{~N}\left(\mathrm{CH}_{3}\right)_{4}\right]$ by fumaric acid to obtain transparent and stable manganese dioxide gels [18]. Stable manganese oxide sols were also synthesized by reduction of $\mathrm{KMnO}_{4}$ with polyvinyl alcohol in an aqueous medium [25]. Nanostructured $\mathrm{MnO}_{2}$ was synthesized at ambient

\footnotetext{
* Corresponding authors at: Ruđer Bošković Institute, Bijenička 54, 10000 Zagreb, Croatia.

E-mail addresses: ivanda@irb.hr (M. Ivanda), gotic@irb.hr (M. Gotić).
} 
conditions by reduction of potassium permanganate with aniline [26]. In our previous work $[27,28]$, the oxidation of aqueous solutions of manganese (II) chloride by hydrogen peroxide was employed to synthesize pure $20-30-\mathrm{nm}$ pseudospherical hausmannite $\left(\mathrm{Mn}_{3} \mathrm{O}_{4}\right)$ nanoparticles and manganite $(\gamma-\mathrm{MnOOH})$ nanowires, whereas the $\alpha-\mathrm{MnO}_{2}$ nanotubes and nanorods were hydrothermally synthesized starting from a $\mathrm{KMnO}_{4}$ precursor. The synthesized manganese oxide NPs induced intracellular oxidative stress in epithelial cells [27] and showed a cytotoxic effect on cancer cells [28].

Generally, the $\gamma$-radiolytic synthesis is a powerful technique for the synthesis of noble metals [29-32] and metal oxide nanoparticles [33-36]. It takes advantage of high-energy $\gamma$-radiation $(1.25 \mathrm{MeV}$ for ${ }^{60} \mathrm{Co} \gamma$-rays) that is able to ionize an aqueous phase. $\gamma$-irradiation of aqueous solutions or suspensions generates a variety of species, such as free radicals $\left(\mathrm{e}_{\mathrm{aq}}{ }^{-}, \mathrm{H}^{\cdot},{ }^{\circ} \mathrm{OH}, \mathrm{HO}_{2}{ }^{\circ}\right)$ and molecular products $\left(\mathrm{H}_{2}, \mathrm{H}_{2} \mathrm{O}_{2}\right)$. $\gamma$-irradiation produces reductive radicals (mostly $\mathrm{e}_{\mathrm{aq}}{ }^{-}$and $\mathrm{H}^{\circ}$ ) homogenously throughout the sample. By adjusting the irradiation dose and dose rate, the atmosphere and $\mathrm{pH}$ of irradiated suspensions, as well as the reducing conditions, size, shape, and phase composition of formed metal and metal oxide NPs can be appropriately controlled [31-34,36,37]. Lume-Pereira et al. [38] prepared Mn(IV) and Mn(III) oxide transparent sols by $\gamma$-irradiating solutions of potassium permanganate $\left(\mathrm{KMnO}_{4}\right)$. A fast comproportionation reaction between $\mathrm{Mn}^{2+}$ and $\mathrm{Mn}^{4+}$ centers at the surface of the colloidal particles was postulated in alkaline sols. Nanocrystalline manganese dioxide $\left(\mathrm{MnO}_{2}\right)$ and manganese(III) oxide $\left(\mathrm{Mn}_{2} \mathrm{O}_{3}\right)$ powders were prepared by $\gamma$-irradiation of potassium permanganate $\left(\mathrm{KMnO}_{4}\right)$ aqueous solution [38-40]. $\mathrm{Hu}$ et al. [41] prepared uniform single-crystal compass-shaped $\mathrm{Mn}_{3} \mathrm{O}_{4}$ nanocrystals using $\gamma$-irradiation. $\mathrm{Mn}(\mathrm{II})$ sulfate and cetyltrimethylammonium bromide (CTAB) were used as a precursor. The authors proposed that firstly $\mathrm{Mn}^{2+}$ was reduced into $\mathrm{Mn}^{0}$ atoms by $\gamma$ ray irradiation and then, $\mathrm{Mn}^{0}$ atoms were quickly oxidized into $\mathrm{Mn}_{3} \mathrm{O}_{4}$ by oxygen in the air.

Typically, throughout the $\gamma$-irradiation synthesis approach various polymers and surfactants can be used as nanoparticle dispersants, surface stabilizers, growth modifiers, and reducing agents [29,31,36,37]. Polymers inhibit coalescence and aggregation of metal oxide NPs through steric hindrances or electrostatic repulsion. In addition to inhibiting aggregation and increasing the colloidal stability of NPs, polymers and surfactants can kinetically control the growth of specific facets thus affecting the particle morphology [36]. For instance, the diethylaminoethyl-dextran hydrochloride (DEAE-dextran) is a hydrophilic, cationic polymer which is biocompatible and able to stabilize nanoparticles electrostatically and sterically. It stabilizes the nanoparticles at an early stage of formation, thus allowing exceptional dispersivity and stability. In this manner, each nanoparticle achieves good contact with the reducing species generated upon $\gamma$-irradiation. In our previous work, DEAE-dextran was used for the synthesis of gold [31] and silver [32] nanoparticles as well as for the synthesis of $\delta-\mathrm{FeOOH}$ nanodiscs [36].

Here, we present the radiolytic synthesis of manganese oxide nanoparticles in the presence or absence of DEAE-dextran. The subsequent radiolytic synthesis yielded amorphous nanoparticles as well as $\mathrm{Mn}_{2} \mathrm{O}_{3}$, $\mathrm{K}_{\mathrm{x}} \mathrm{MnO}_{2}$, and $\mathrm{Mn}_{3} \mathrm{O}_{4}$ nanoparticles. The synthesized nanoparticles were characterized using X-ray powder diffraction (XRD), Scanning Electron Microscopy (SEM), Raman spectroscopy, Multiple Angle Dynamic Light Scattering (MADLS), UV-Vis diffuse reflectance, and $\mathrm{N}_{2}$ adsorptiondesorption measurements. In addition, the synthesized manganese oxide samples were applied for decolorization of methylene blue (MB) aqueous solutions. The radiolytically synthesized $\mathrm{Mn}_{3} \mathrm{O}_{4} \mathrm{NPs}$ in the absence of DEAE-dextran polymer (zeta potential of $-39.4 \mathrm{mV}$, BET surface area of $234 \mathrm{~m}^{2} \mathrm{~g}^{-1}$ and pore volume of $1.52 \mathrm{~cm}^{3} \mathrm{~g}^{-1}$ ) showed the highest MB decolorization effect.

\section{Materials and methods}

\subsection{Materials}

Potassium permanganate $\left(\mathrm{KMnO}_{4}\right)$, sodium hydroxide $(\mathrm{NaOH})$, 2propanol $\left.\left(\left(\mathrm{CH}_{3}\right)_{2} \mathrm{CHOH}\right)\right)$ and glycerol were supplied by Kemika. Diethylaminoethyl-dextran hydrochloride (DEAE-dextran) powder (prepared from dextran of average mol. wt. 500,000) was supplied by Sigma-Aldrich. Methylene blue was supplied by Merck and $96 \%$ ethanol was supplied by GramMol. All chemicals were of analytical purity and were used without further purification. High-purity water with a resistivity of $18 \mathrm{M} \Omega \mathrm{cm}^{-1}$ was used in all experiments.

\subsection{Sample synthesis}

A stock solution of $\mathrm{KMnO}_{4}$ was prepared by dissolving $278.15 \mathrm{mg}$ of $\mathrm{KMnO}_{4}$ in $100 \mathrm{~mL}$ of water $\left(\mathrm{c}=17.6 \mathrm{mmol} \mathrm{L}^{-1}\right)$. Sample precursor solutions were prepared by dissolving appropriate amount $(1.89 \mathrm{~g}$ or $0.945 \mathrm{~g}$ ) of DEAE-dextran in $\mathrm{KMnO}_{4}$ stock solution. Using a $10 \mathrm{M} \mathrm{NaOH}$ solution, the $\mathrm{pH}$ of the sample solutions was adjusted to $\mathrm{pH} 9-10$. The color of the sample solutions did not change upon the addition of $\mathrm{NaOH}$. 2-propanol (final concentration $0.2 \mathrm{M}$ ) was added to the reaction solution in order to enhance reducing conditions [37]. The prepared precursor solutions were bubbled with nitrogen gas $\left(\mathrm{N}_{2}\right)$ for at least $15 \mathrm{~min}$ to remove dissolved oxygen before $\gamma$-irradiation.

The precursor suspensions were $\gamma$-irradiated at room temperature using ${ }^{60} \mathrm{Co} \gamma$-rays in a panoramic source constructed by Radiation Chemistry and Dosimetry Laboratory of the Ruđer Bošković Institute, Zagreb, Croatia. The dose rate of $\gamma$-irradiation was $\sim 32 \mathrm{kGy} \mathrm{h}^{-1}$ and absorbed doses were 100 and $200 \mathrm{kGy}$.

As-synthesized samples were centrifuged using Scanspeed 2236R high-speed centrifuge and washed several times with ultrapure water and two times with ethanol $(8000 \mathrm{rpm}, 15 \mathrm{~min})$. The obtained precipitates were dried under vacuum at room temperature and then characterized as powders.

\subsection{Microstructural and optical characterizations}

The morphology of the obtained materials was studied by field emission scanning electron microscope (Jeol JSM 7000F) coupled with Energy-dispersive spectroscopy (EDS).

X-ray powder diffraction (XRD) patterns were recorded at room temperature using the APD 2000 X-ray powder diffractometer $(\mathrm{CuK} \alpha$ radiation, graphite monochromator, NaI-Tl detector) (ItalStructures, Riva Del Garda, Italy). The XRD patterns were recorded over the $5-80^{\circ}$ $2 \theta$ range with a $2 \theta$ step of $0.05^{\circ}$ and a counting time per step of 23-37 s. Size-strain and line-broadening analysis of the $\mathrm{Mn}_{3} \mathrm{O}_{4}$ phase in the M9 and M9G samples was performed using the results of Williamson-Hall analysis [42]. The values of volume-averaged domain size $\left(D_{\mathrm{v}}\right)$ and the upper-limits of microstrains $(e)$ were estimated from the results of Williamson-Hall analysis (Fig. S2) by using the equation:

$\left(\frac{\beta \cos \theta}{\lambda}\right)=\frac{K}{D_{v}}\left(\frac{4 e \sin \theta}{\lambda}\right)$

where $\lambda$ is wavelength, $\beta$ stands for the physical broadening of diffraction line and $K$ is a constant close to 0.9 . The $\beta$ values were obtained by convolution-fitting approach (software SHADOW [43]) in which the instrumental profile (diffraction lines of well-crystalline zincite powder [44]) is convoluted with a refinable Voigt function to fit the observed profile.

Dynamic light scattering (DLS) measurements were performed by Zetasizer Ultra (Malvern Panalytical) which offers Multi-Angle Dynamic Light Scattering (MADLS ${ }^{\circledR}$ ) measurements. The samples were re-dispersed in water and the measurements were performed at room temperature. The size distributions given by MADLS were reported as 
volume distribution, and results are presented as the mean value of at least 2 measurements performed at back-scatter, side-scatter, and forward-scatter angles. Zeta potential was taken as the mean value of five measurements.

The Raman spectra were recorded by Horiba Jobin Yvon T64000 triple Raman spectrometer with $532 \mathrm{~nm}$ diode laser. In order to reduce the photodegradation of the samples, filters were used, and the laser excitation power was kept low, at about $5 \mathrm{~mW}$. Raman spectra on powder samples were acquired using a $\times 50$ microscope objective. Temperature-dependent Raman measurements were carried out in situ at different temperatures using a Linkam (THMS600) temperature controlled stage.

The surface structure parameters of the obtained manganese oxides were determined by $\mathrm{N}_{2}$ adsorption-desorption measurements. Prior to the measurement, the material was kept for $10 \mathrm{~h}$ at $110^{\circ} \mathrm{C}$ under vacuum to remove any residual gas and moisture from the sample. The adsorption-desorption isotherms were measured by Autosorb iQ-AG-C Quantachrome instrument at $77 \mathrm{~K}$. The Brunauer-Emmet-Teller (BET) method was used to determine the specific surface area. The pore volume versus diameter distribution was calculated by analyzing the desorption branch of the isotherm using the Barrett-Joyner-Halenda (BJH) method.

\subsection{Decolorization of methylene blue}

In the decolorization experiments, $45 \mathrm{mg}$ of powdered sample was weighed and dispersed in $270 \mathrm{~mL}$ of Milli-Q water and then ultrasonicated for approximately $10 \mathrm{~min}$. $30 \mathrm{~mL}$ of methylene blue solution $\left(0.2 \mathrm{~g} \mathrm{~L}^{-1}\right)$ was added to the previously prepared aqueous suspension $(270 \mathrm{~mL})$ and the whole suspension $(300 \mathrm{~mL})$ was magnetically stirred. The $\mathrm{pH}$ of the suspension was measured, and $\mathrm{HCl}$ solution ( $\mathrm{c}=2 \mathrm{~mol} \mathrm{dm}^{-3}$ ) was slowly added until the $\mathrm{pH}$ of the suspension reached $\mathrm{pH}=2$. At given time intervals, aliquots of the suspension were taken and immediately centrifuged to remove the sample catalyst. The resulting supernatant was collected and analyzed by a Shimadzu UV 3600 spectrophotometer in the range from 1200 to $300 \mathrm{~nm}$.

\section{Results and discussion}

\subsection{Synthesis of MnO nanostructures under various conditions}

The radiolytic synthesis is a powerful method for the synthesis of metal and metal oxide NPs. However, since the precursor suspensions have not been stirred, it is necessary to avoid possible aggregation of the nanoparticles upon $\gamma$-irradiation. Thus, the use of polymers will stabilize the nanoparticles in suspension, so that every particle will be in good contact with the generated reducing species. Here, we used hydrophilic polymer amino-dextran, i.e. the diethylaminoethyl-dextran hydrochloride (DEAE-dextran) as a stabilizing agent. DEAE-dextran has never been used for the radiolytic synthesis of Mn-oxides.

In this work, the manganese oxide nanoparticles were radiolytically synthesized starting from $\mathrm{KMnO}_{4}$ precursor in the presence (samples M1 - M6) or absence (samples M7 - M9) of DEAE-dextran. The absorbed doses were 100 and $200 \mathrm{kGy}$. The annotation and experimental conditions for the synthesis of the samples as well as the results of XRD and Raman analyses, and the values of BET surface areas, hydrodynamic diameters and zeta potential are given in Table 1. As seen in Table 1, samples synthesized in the presence of $\gamma$-irradiation and DEAEdextran contained N-Butyloxy-carbonyl- $\mathrm{N}^{\prime}$-(p-ethoxy-phenyl)-ethylenediamine $\left(\mathrm{C}_{15} \mathrm{H}_{24} \mathrm{~N}_{2} \mathrm{O}_{3}\right)$ that might be formed due to the radiolytic degradation of DEAE-dextran. Furthermore, the use of DEAE-dextran significantly reduced the BET surface areas of Mn-oxides in comparison to the radiolytically synthesized Mn-oxides in the absence of DEAEdextran.

\subsection{Characterization of $\mathrm{MnO}$ nanostructures}

Fig. 1 shows SEM images of isolated powder samples M4 (A), M6 (B), M8 (C) and M9 (D). The SEM image of sample M4 shows nanoparticles trapped in a continuous amorphous matrix with no visible discrete nanoparticles. This is in line with BET specific surface area of only $10.9 \mathrm{~m}^{2} \mathrm{~g}^{-1}$ (Table 1 ) measured for sample M4. The SEM image of sample M6 shows diffuse aggregates of very small nanoparticles, whereas the discrete nanoparticles are partially visible. The SEM images of samples M8 and M9 show softly aggregated pseudospherical nanoparticles of about $50 \mathrm{~nm}$ in size. The nanoparticles are more discrete and the particle boundaries are more clearly visible in sample M9 in comparison to sample M8. This is in accordance with the BET specific surface areas of $233.8 \mathrm{~m}^{2} \mathrm{~g}^{-1}$ and $147.9 \mathrm{~m}^{2} \mathrm{~g}^{-1}$ for sample M9 and M8, respectively (Table 1 ).

Fig. 2 shows the results of powder X-ray diffraction (XRD) analysis of samples M2 to M9 and sample M9G that was isolated by admixing glycerol. Generally, the XRD patterns of samples synthesized in the absence of $\gamma$-irradiation (samples M1, M4 and M7) and in the presence of DEAE-dextran (M2, M3, M5 and M6) are characterized with broad XRD lines due to the very small crystallite size and/or presence of amorphous phases. The phase analyses (Fig. 2 and Table 1) were made according to the International Centre for Diffraction Data (ICDD) cards. The XRD patterns of samples M5 and M6, in addition to the inorganic $\mathrm{Mn}_{3} \mathrm{O}_{4}$ (hausmannite), also contained an organic phase N-Butyloxy-carbonyl- $\mathrm{N}^{\prime}$-(p-ethoxy-phenyl)-ethylenediamine $\left(\mathrm{C}_{15} \mathrm{H}_{24} \mathrm{~N}_{2} \mathrm{O}_{3}\right.$; card no. 23-1515) that might form due to the radiolytic degradation of DEAE-dextran polymer. The XRD patterns of radiolytically synthesized sample M9 with no polymer consist of broad maxima that match with card no. 52-556 $\left(\mathrm{K}_{0.27} \mathrm{MnO}_{2} \cdot 0.54 \mathrm{H}_{2} \mathrm{O}\right)$ and relatively sharp lines that match with card no. 24-734 $\left(\mathrm{Mn}_{3} \mathrm{O}_{4}\right.$, hausmannite). In accordance with our previous work [36], we suppose that radiolytically synthesized metal oxide NPs of transition metals, which possess low valence metals such as $\mathrm{Fe}(\mathrm{II})$ in $\mathrm{Fe}(\mathrm{OH})_{2}$, and/or $\mathrm{Fe}_{3} \mathrm{O}_{4}$ (magnetite) can be oxidized upon the conventional process of isolation (washing/centrifugation). Due to this reason, we synthesized sample M9 and isolated the precipitate by admixing glycerol (sample M9G). In this way, glycerol that contains hydroxyl groups retarded the oxidation of otherwise very oxidation-sensitive compounds [45]. Glycerol chemisorbs on to the oxygen sensitive nanoparticles and then, the glycerol hydroxy groups easily oxidize to aldehyde or carboxylic acid groups, which lowers the probability of oxygen reaching and oxidizing the structural low-valence metal cations such as $\mathrm{Mn}$ (II). Therefore, the sample M9G isolated by admixing glycerol contained exclusively the $\mathrm{Mn}_{3} \mathrm{O}_{4}$, which is the more reduced product in comparison to the conventionally isolated sample M9 that contained two phases, $\mathrm{K}_{0.27} \mathrm{MnO}_{2} \cdot 0.54 \mathrm{H}_{2} \mathrm{O}$ and $\mathrm{Mn}_{3} \mathrm{O}_{4}$.

Hausmannite $\left(\mathrm{Mn}_{3} \mathrm{O}_{4}\right)$ and potassium manganese oxide hydrate $\left(\mathrm{K}_{0.27} \mathrm{MnO}_{2} \cdot 0.54 \mathrm{H}_{2} \mathrm{O}\right)$ volume average domain sizes were estimated using Scherrer equation:

$D_{v}(h k l)=\frac{0.9 \lambda}{\beta_{h k l} \cos \theta}$

where $D_{\mathrm{v}}(\mathrm{hkl})$ is a volume average domain size in the direction normal to the reflecting planes $(h k l), \lambda$ is the $\mathrm{x}$-ray wavelength $(\mathrm{CuK} \alpha)$, $\theta$ is the Bragg angle and $\beta_{h k l}$ is the pure full width of the diffraction line ( $h k l$ ) at half the maximum intensity. The $D_{\mathrm{v}}(101)$ values of $\mathrm{Mn}_{3} \mathrm{O}_{4}$ in samples M9 and M9G are estimated to 44 and $38 \mathrm{~nm}$, respectively, whereas the $D_{\mathrm{v}}(006)$ values of $\mathrm{K}_{0.27} \mathrm{MnO}_{2} \cdot 0.54 \mathrm{H}_{2} \mathrm{O}$ in samples $\mathrm{M} 8$ and M9 are estimated to 2.6 and $3.4 \mathrm{~nm}$, respectively (Table 1). The results of the size-strain analysis, obtained using Williamson-Hall plot (Fig. S2 in Supplementary Material), indicate the presence of small microstrain $\left(e \sim 4 \times 10^{-3}\right)$ in the $\mathrm{Mn}_{3} \mathrm{O}_{4}$ phase of samples M9 and M9G. The $D_{\mathrm{v}}$ values obtained from the Williamson-Hall plot are somewhat bigger compared to the $D_{\mathrm{v}}$ values estimated using Scherrer equation, $\sim 47 \mathrm{~nm}$ and $\sim 40 \mathrm{~nm}$ in samples M9 and M9G, respectively. 
Table 1

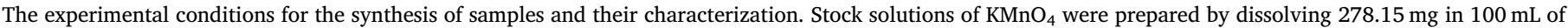
water and the dose rate was $\sim 32 \mathrm{kGy} \mathrm{h}^{-1}$.

\begin{tabular}{|c|c|c|c|c|c|c|c|c|c|}
\hline Sample & $\begin{array}{l}\rho \text { (DEAE- } \\
\text { dextran) } \\
(\mathrm{mg} / \mathrm{mL})\end{array}$ & $\mathrm{N}_{2}$ bubbling & $\begin{array}{l}\text { Dose } \\
\text { (kGy) }\end{array}$ & Phase composition & $\begin{array}{l}\text { Raman } \\
\text { bands } \\
\left(\mathrm{cm}^{-1}\right)\end{array}$ & $\begin{array}{l}\text { BET } \\
\text { surface } \\
\text { area } \\
\left(\mathrm{m}^{2} \mathrm{~g}^{-1}\right)\end{array}$ & $\begin{array}{l}\text { Volume-averaged } \\
\text { domain size (nm) }\end{array}$ & $\begin{array}{l}\text { Hydrodynamic } \\
\text { diameter }^{\mathrm{b}}(\mathrm{nm})\end{array}$ & $\begin{array}{l}\text { Zeta } \\
\text { potential } \\
(\mathrm{mV})\end{array}$ \\
\hline M1 & 18.9 & - & - & Amorphous & - & 13.9 & & - & +4.4 \\
\hline M2 & 18.9 & + & 100 & Amorphous $+\mathrm{Mn}_{2} \mathrm{O}_{3}\left(\mathrm{VBDL}^{\mathrm{a}}\right)$ & - & 6.3 & & $\begin{array}{l}124(14.5 \%) \\
333(28.4 \%) \\
668(57.1 \%)\end{array}$ & +20.0 \\
\hline M3 & 18.9 & + & 200 & Amorphous $+\mathrm{Mn}_{2} \mathrm{O}_{3}$ (VBDL) & $\begin{array}{l}650 \\
\text { (broad) }\end{array}$ & 13.3 & & $\begin{array}{l}119(22.8 \%) \\
407(45.6 \%) \\
1260(31.6 \%)\end{array}$ & - \\
\hline M4 & 9.45 & - & - & $\mathrm{K}_{\mathrm{x}} \mathrm{MnO}_{2}(\mathrm{VBDL})+$ Amorphous & 570,625 & 10.9 & & - & - \\
\hline M5 & 9.45 & + & 100 & $\begin{array}{l}\mathrm{Mn}_{3} \mathrm{O}_{4} \\
(\mathrm{VBDL})+\mathrm{C}_{15} \mathrm{H}_{24} \mathrm{~N}_{2} \mathrm{O}_{3}+\text { Amorphous }\end{array}$ & 650 & 1.0 & & $\begin{array}{l}141(39.1 \%) \\
440(43.0 \%) \\
1175(17.9 \%)\end{array}$ & +17.9 \\
\hline M6 & 9.45 & + & 200 & $\begin{array}{l}\mathrm{Mn}_{3} \mathrm{O}_{4} \\
(\mathrm{VBDL})+\mathrm{C}_{15} \mathrm{H}_{24} \mathrm{~N}_{2} \mathrm{O}_{3}+\text { Amorphous }\end{array}$ & $\begin{array}{l}650 \\
\text { (broad) }\end{array}$ & 21.0 & & $\begin{array}{l}461(76.4 \%) \\
1380(15.3 \%) \\
4530(8.3 \%)\end{array}$ & - \\
\hline M7 & - & - & - & Amorphous $+\mathrm{MnO}_{2}$ (VBDL) & 570 & 3.5 & & - & - \\
\hline M8 & - & + & 100 & $\begin{array}{l}\mathrm{K}_{0.27} \mathrm{MnO}_{2} \cdot 0.54 \mathrm{H}_{2} \mathrm{O} \\
\text { (VBDL) + Amorphous }\end{array}$ & 560 & 147.9 & $2.6\left(\mathrm{~K}_{0.27} \mathrm{MnO}_{2}\right)$ & $\begin{array}{l}162(37.2 \%) \\
366(20.3 \%) \\
686(52.7 \%)\end{array}$ & -51.0 \\
\hline M9 & - & + & 200 & $\mathrm{Mn}_{3} \mathrm{O}_{4}+\mathrm{K}_{\mathrm{x}} \mathrm{MnO}_{2}(\mathrm{VBDL})+$ Amorphous & 632 & 233.8 & $\begin{array}{l}44\left(\mathrm{Mn}_{3} \mathrm{O}_{4}\right) \\
3.4\left(\mathrm{~K}_{0.27} \mathrm{MnO}_{2}\right)\end{array}$ & $\begin{array}{l}110(63.9 \%) \\
386(36.1 \%)\end{array}$ & -39.4 \\
\hline M9G $^{\mathrm{c}}$ & - & + & 200 & $\mathrm{Mn}_{3} \mathrm{O}_{4}$ & $\begin{array}{l}660 \\
\text { (sharp) }\end{array}$ & & $38\left(\mathrm{Mn}_{3} \mathrm{O}_{4}\right)$ & - & - \\
\hline
\end{tabular}

${ }^{\text {a }}$ VBDL $=$ Very broadened diffraction lines.

b The results of multiple angle dynamic light scattering (MADLS) analysis. The multiple hydrodynamic diameters correspond to mean values of different populations, whereas the percentages in brackets represent the volume percent based on volume distributions.

c Sample was isolated by admixing glycerol.
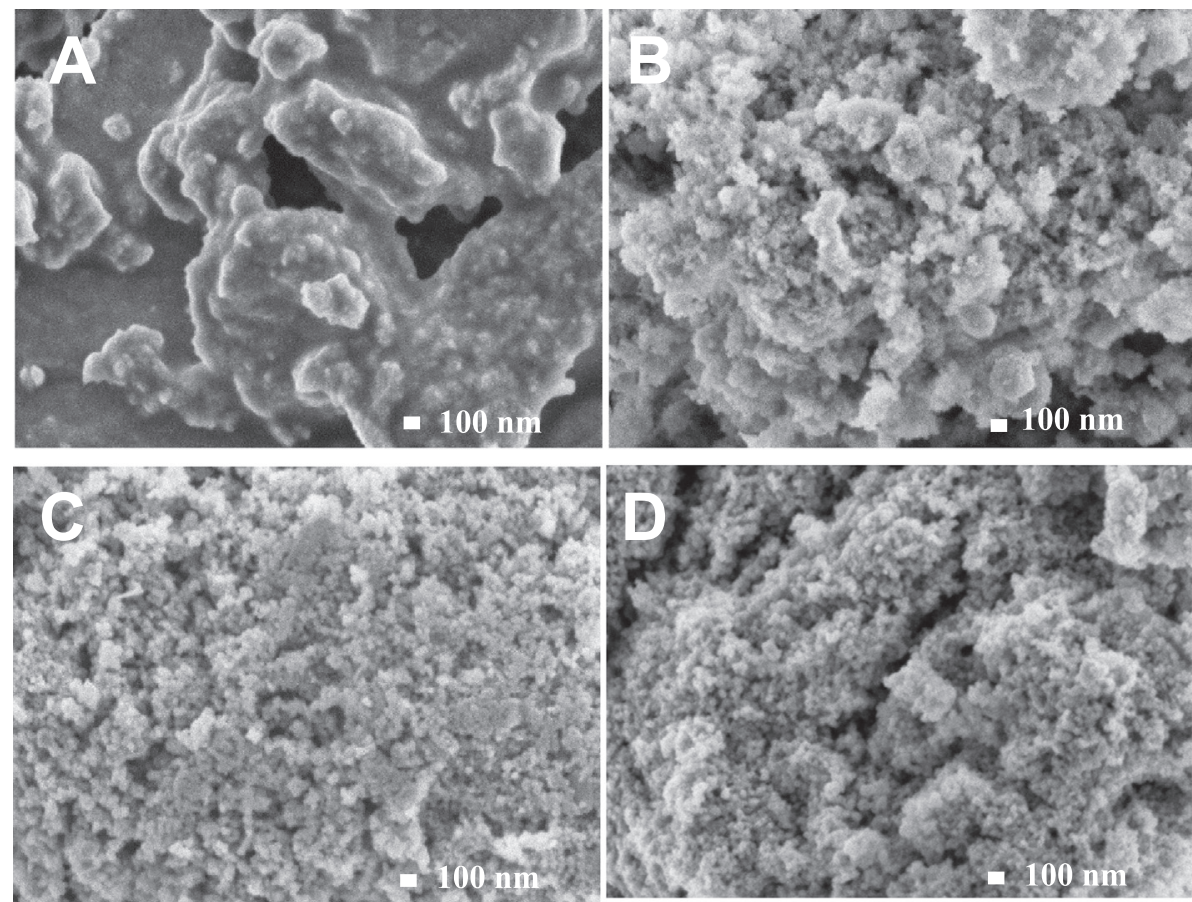

Fig. 1. SEM images of samples M4 (A), M6 (B), M8 (C) and M9 (D).

Fig. 3 shows Raman spectra of powder samples M1 to M9 (a) and sample M9G. Raman bands are rather broad, suggesting the presence of amorphous phases. The broad Raman bands at around 630 to $650 \mathrm{~cm}^{-1}$ (M3, M4, M5, M6 and M9) may be assigned to the Mn-O symmetric stretching. The band at $650 \mathrm{~cm}^{-1}$ (samples M3 and M4) indicates the presence of $\mathrm{Mn}_{3} \mathrm{O}_{4}$, while the band at $570 \mathrm{~cm}^{-1}$ (samples M4, M7) indicates a contribution from $\mathrm{MnO}_{2}$. The sample M9G (Fig. 3b) shows a sharp peak at $660 \mathrm{~cm}^{-1}$, which is characteristic for $\mathrm{Mn}_{3} \mathrm{O}_{4}$. The Raman region at $2800-3000 \mathrm{~cm}^{-1}$ (C-H stretching region), exhibits several broad Raman bands probably due to the adsorbed organic compounds.

Fig. 4 shows the $\mathrm{N}_{2}$ adsorption-desorption isotherms (a) and the corresponding pore size distributions (b) of samples M6, M8, and M9. The samples exhibit the reversible Type II physisorption isotherms. This shape is the result of unrestricted monolayer-multilayer adsorption. The 

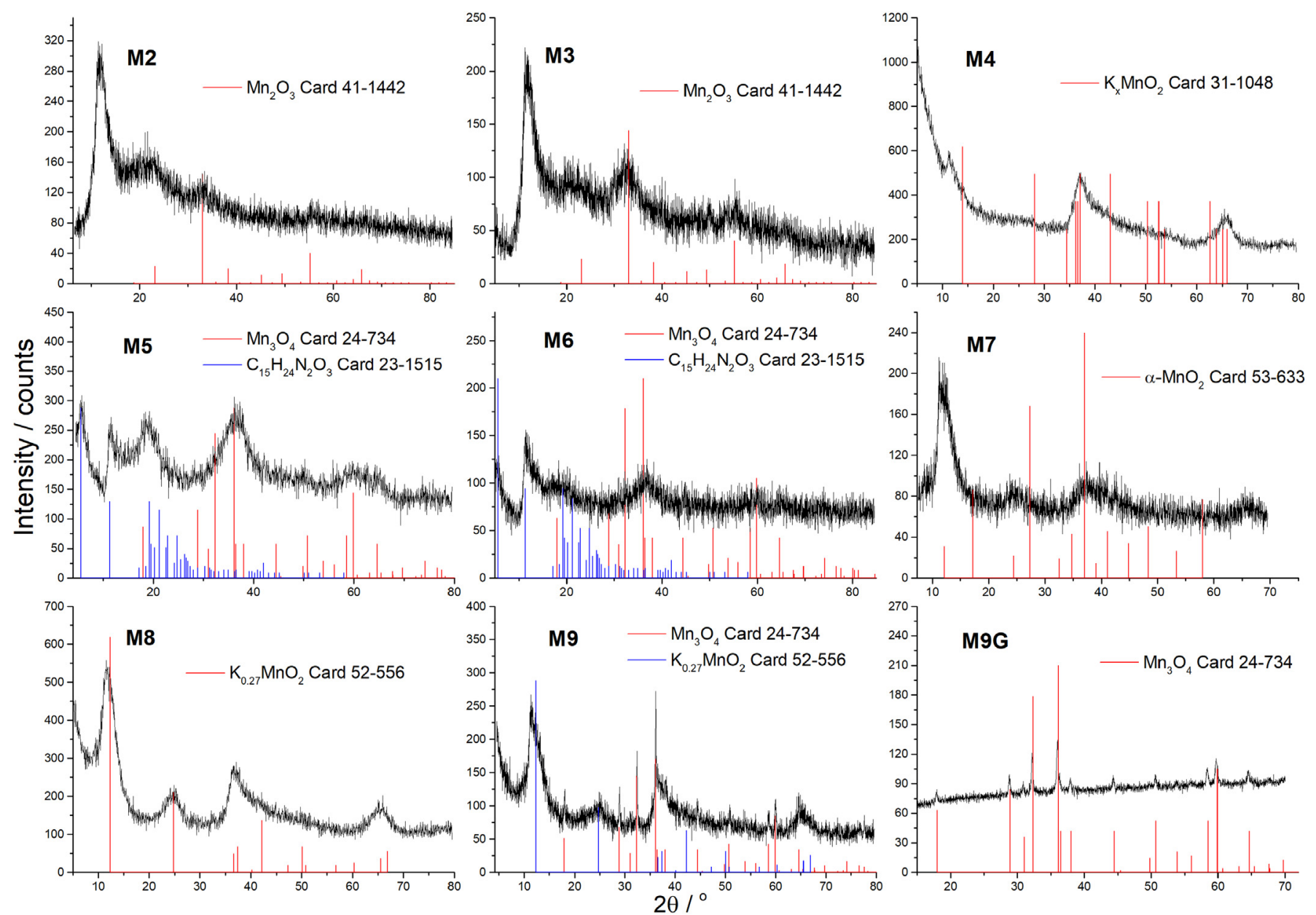

Fig. 2. The XRD patterns of powder samples M2 to M9 and sample M9G that was isolated by admixing glycerol.
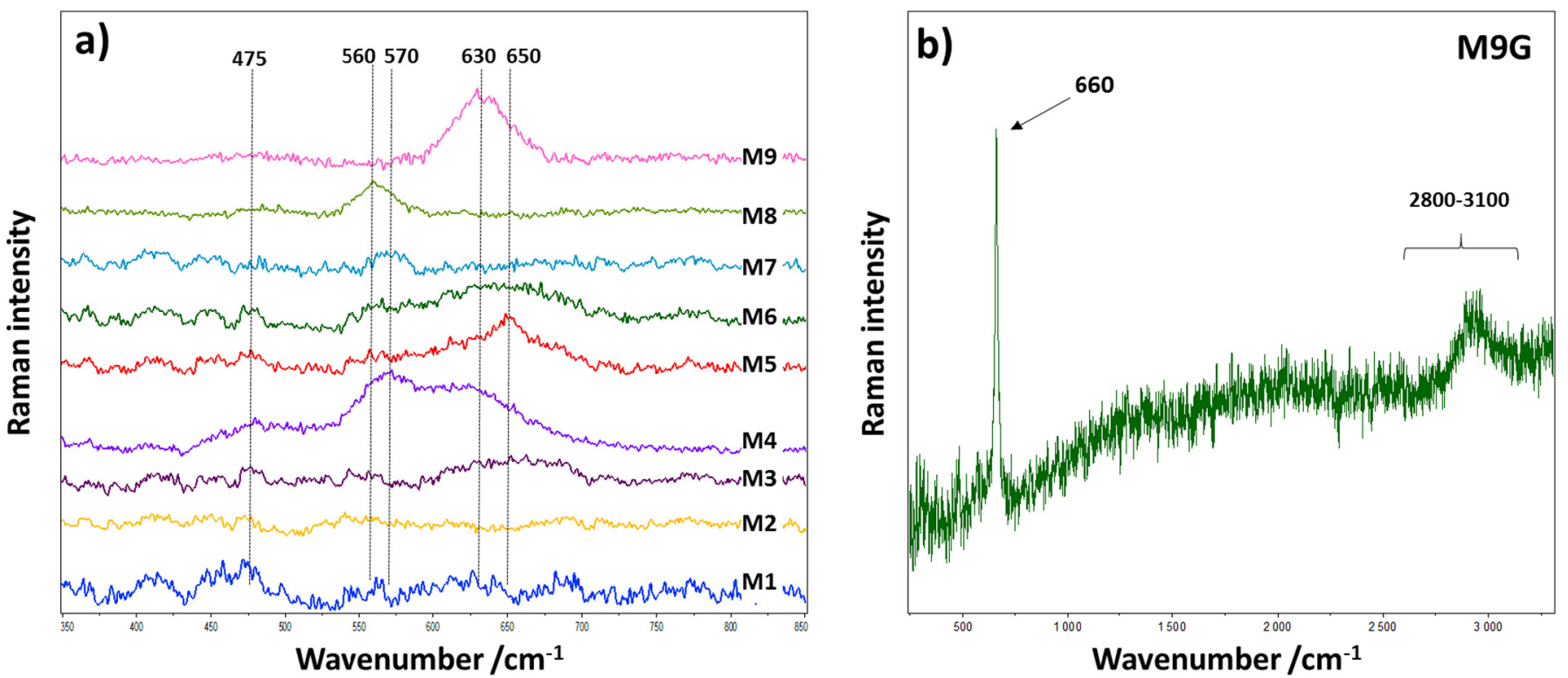

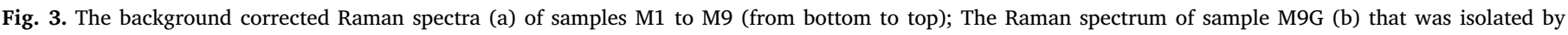
admixing glycerol.

nitrogen gas uptake increases sharply up to a low value of $\mathrm{p} / \mathrm{p}_{0}$ which indicates the completion of monolayer coverage, and then linearly increases up to a $\mathrm{p} / \mathrm{p}_{0}$ of 0.8 , which indicates the stage at which multilayer forms. After the $\mathrm{p} / \mathrm{p}_{0}$ of 0.8 , the nitrogen uptake increases much more steeply (multilayer thickness is without limit). Cumulative pore volume (black line) and the pore radius distributions (blue line) are shown in the insets. The pore volume of sample M6 synthesized in the presence of DEAE-dextran is an order of magnitude lower 

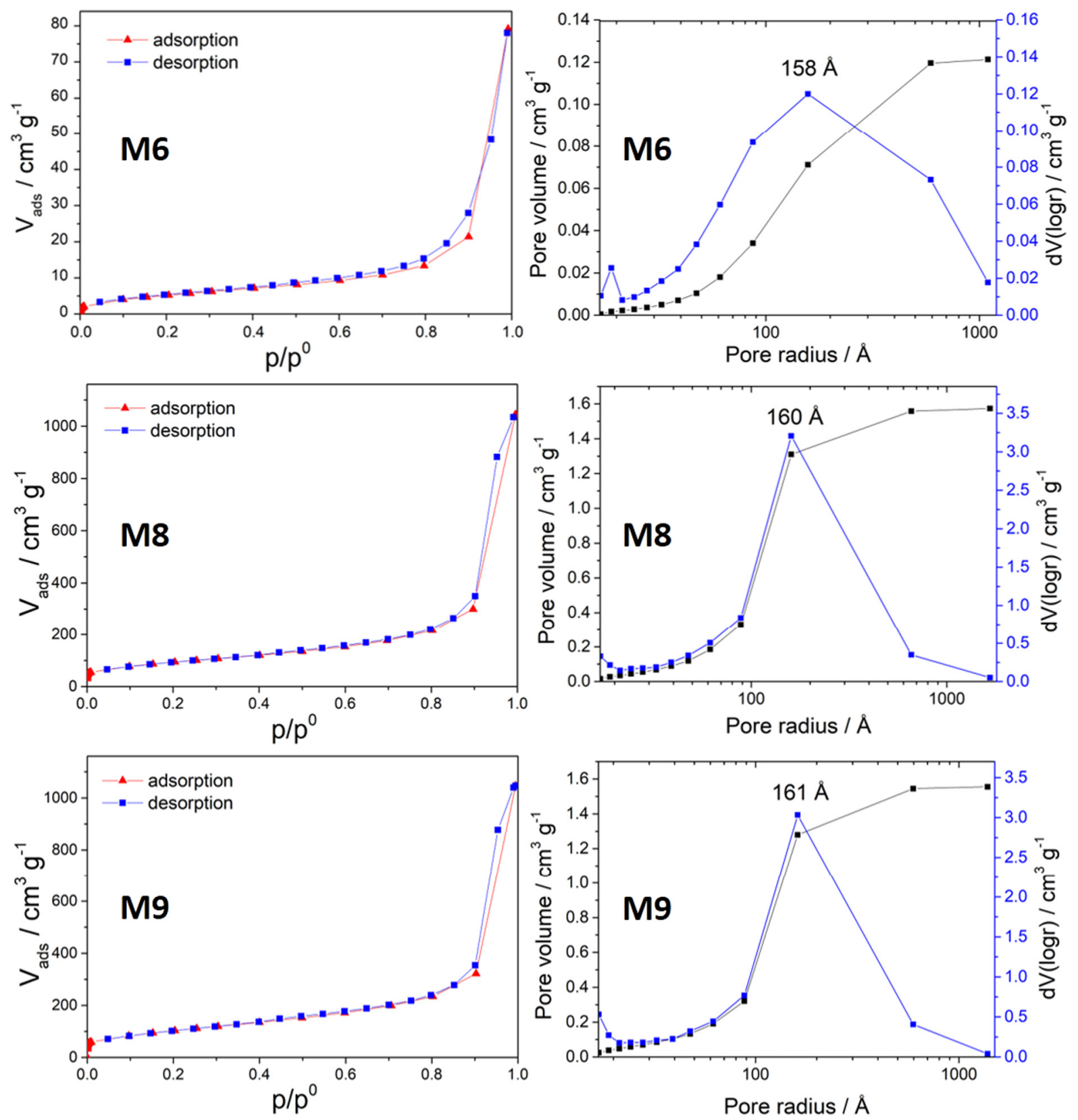

a)

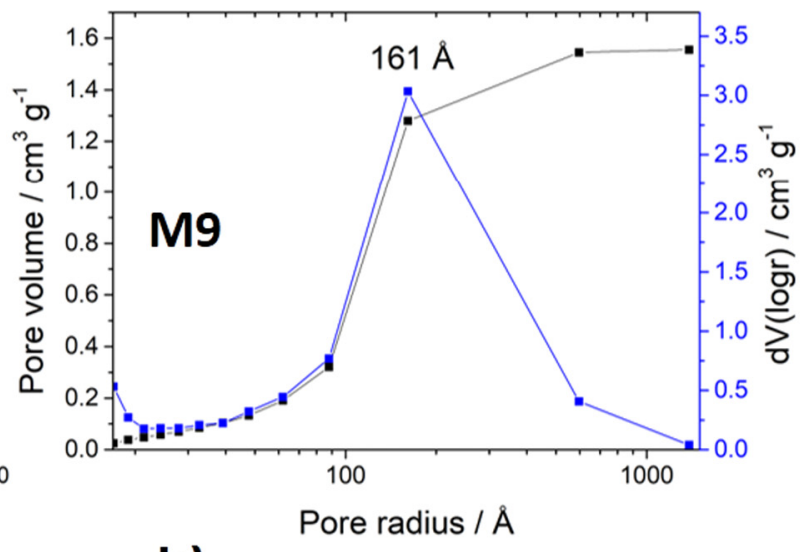

b)

Fig. 4. Gas $\left(\mathrm{N}_{2}\right)$ adsorption (red line, triangles) and desorption (blue line, squares) isotherms of M6, M8 and M9 samples (a) and corresponding cumulative pore volume (black line) and pore radius distributions (blue line) determined by the Barrett-Joyner-Halenda (BJH) method (b). (For interpretation of the references to color in this figure legend, the reader is referred to the web version of this article.)

$\left(0.12 \mathrm{~cm}^{3} \mathrm{~g}^{-1}\right)$ in comparison to the samples M8 and M9 synthesized in the absence of polymer $\left(1.52 \mathrm{~cm}^{3} \mathrm{~g}^{-1}\right)$. Although the pore radius is similar in all three samples $(\sim 160 \AA)$ the pore radius distribution of sample M6 is much broader in comparison to the pore radius distributions of samples M8 and M9.

Fig. 5 shows UV-Vis diffuse reflectance spectra (a) of samples M6, M8, and M9 and the corresponding Kubelka-Munk plots (b). Diffuse reflectance spectra of other samples, as well as diffuse reflectance spectra of samples M6G and M9G that were isolated by admixing glycerol, can be found in the Supplementary Material (Fig. S3). The band gap energy of samples M6, M8, and M9 was calculated based on the Kubelka-Munk function. The following relation is used:

$(h v \alpha)^{\frac{1}{n}}=A\left(h \nu-E_{g}\right)$ where $\mathrm{h}$ is Planck's constant, $\nu$ is frequency, $\alpha$ is absorption coefficient, $\mathrm{E}_{\mathrm{g}}$ is band gap and $\mathrm{A}$ is proportionality constant. The value of the exponent $\mathrm{n}$ represents the type of sample transition $(n=2$ for indirect allowed transition, $n=0.5$ for direct allowed transition). The calculations were performed for direct band gap energy determination; therefore, the value of $\mathrm{n}$ was set to 0.5 . The collected diffuse reflectance spectra were converted to the Kubelka-Munk function. The vertical axis was converted to a quantity $\left[\mathrm{F}\left(\mathrm{R}_{\infty}\right) \mathrm{h} \nu\right]^{2}$ where $\mathrm{F}\left(\mathrm{R}_{\infty}\right)$ is proportional to the absorption coefficient and is calculated by the following equation:

$F\left(R_{\infty}\right)=(1-R)^{2} / 2 R$

where $\mathrm{R}$ is reflectance at a given wavelength. Using the calculated values, $\left[F\left(R_{\infty}\right) h \nu^{2}\right]$ was plotted against $h \nu$. A line tangent to the linear part of the curve was extrapolated to zero reflectance. The extrapolated 

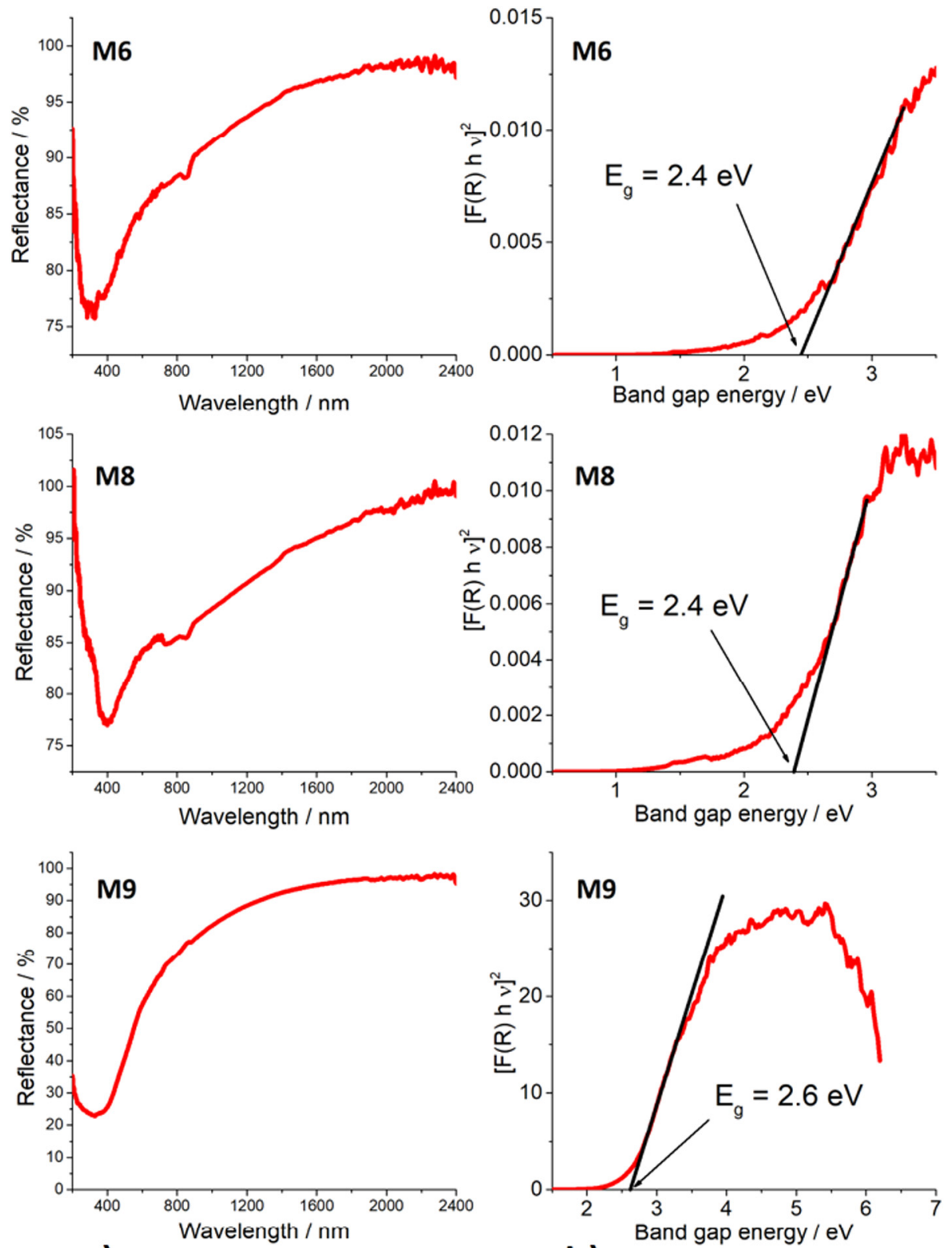

a)

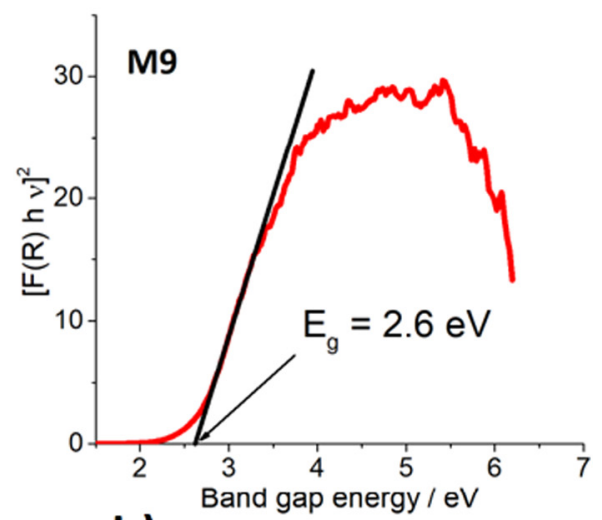

b)

Fig. 5. UV-Vis diffuse reflectance spectra of samples M6, M8 and M9 (a) and corresponding Kubelka-Munk plots. The calculated band gap (E $\mathrm{E}_{\mathrm{g}}$ ) of samples M6, M8, and M9 was estimated to $2.4 \mathrm{eV}, 2.4 \mathrm{eV}$, and $2.6 \mathrm{eV}$, respectively (b).

value was taken as the band gap energy of the material. The calculated band gaps $\left(\mathrm{E}_{\mathrm{g}}\right)$ of samples M6, M8, and M9 were estimated to 2.4, 2.4, and $2.6 \mathrm{eV}$, respectively.

Fig. 6 shows the hydrodynamic size distributions by volume for samples M2 to M9 measured using Multiple Angle Dynamic Light Scattering (MADLS) technology. The abundance (\%) of resolved size populations are given in Table 1 . The results of zeta potential $(\xi)$ measurements are given in the insets of Fig. 6 and in Table 1. Generally, the particles with zeta potential greater than $+20 \mathrm{mV}$ or less than $-20 \mathrm{mV}$ are considered stable and do not sediment in the suspension. The zeta potentials of samples synthesized in the presence of polymer have positive values because the DEAE-dextran is a cationic polymer that has a positive charge over the whole $\mathrm{pH}$ range. The zeta potentials of samples M8 and M9 are -51.0 and $-39.7 \mathrm{mV}$, respectively, so they can be considered very stable. Furthermore, sample M9 has a BET surface area of $234 \mathrm{~m}^{2} \mathrm{~g}^{-1}$ and possesses two populations of $110 \mathrm{~nm}$ $(63.9 \%)$ and $386 \mathrm{~nm}$ (36.1\%), which are the narrowest size distributions among all of the synthesized samples (Fig. 6 and Table 1). Size populations of $>1 \mu \mathrm{m}(>1000 \mathrm{~nm})$ are attributed to the polymer or the degradation products of the polymer during $\gamma$-irradiation.

\subsection{Application of $\mathrm{MnO}$ nanostructures on decolorization of $M B$}

The decolorization of MB organic dye are extensively investigated, however, virtually there is no data about the applications of radiolytically synthesized manganese oxides on decolorization of MB. Fig. 7 shows decolorization experiments at different time intervals in the presence of samples M2 (a), M3 (b), M5 (c), M6 (d), M8 (e) and M9 (f). The concentration of methylene blue (MB) in aqueous solution was $0.02 \mathrm{~g} \mathrm{~L}^{-1}$ and the $\mathrm{pH}$ was adjusted to 2 . The MB aqueous solution by itself does not decolorize at $\mathrm{pH}=2$ as it is shown in Fig. S4 (Supplementary Material). Upon addition of powder samples, these two peaks shifted to the lower wavelengths (blue-shifts, hypsochromic effects) and the new peak arises at $458 \mathrm{~nm}$ thus strongly suggesting the oxidative 

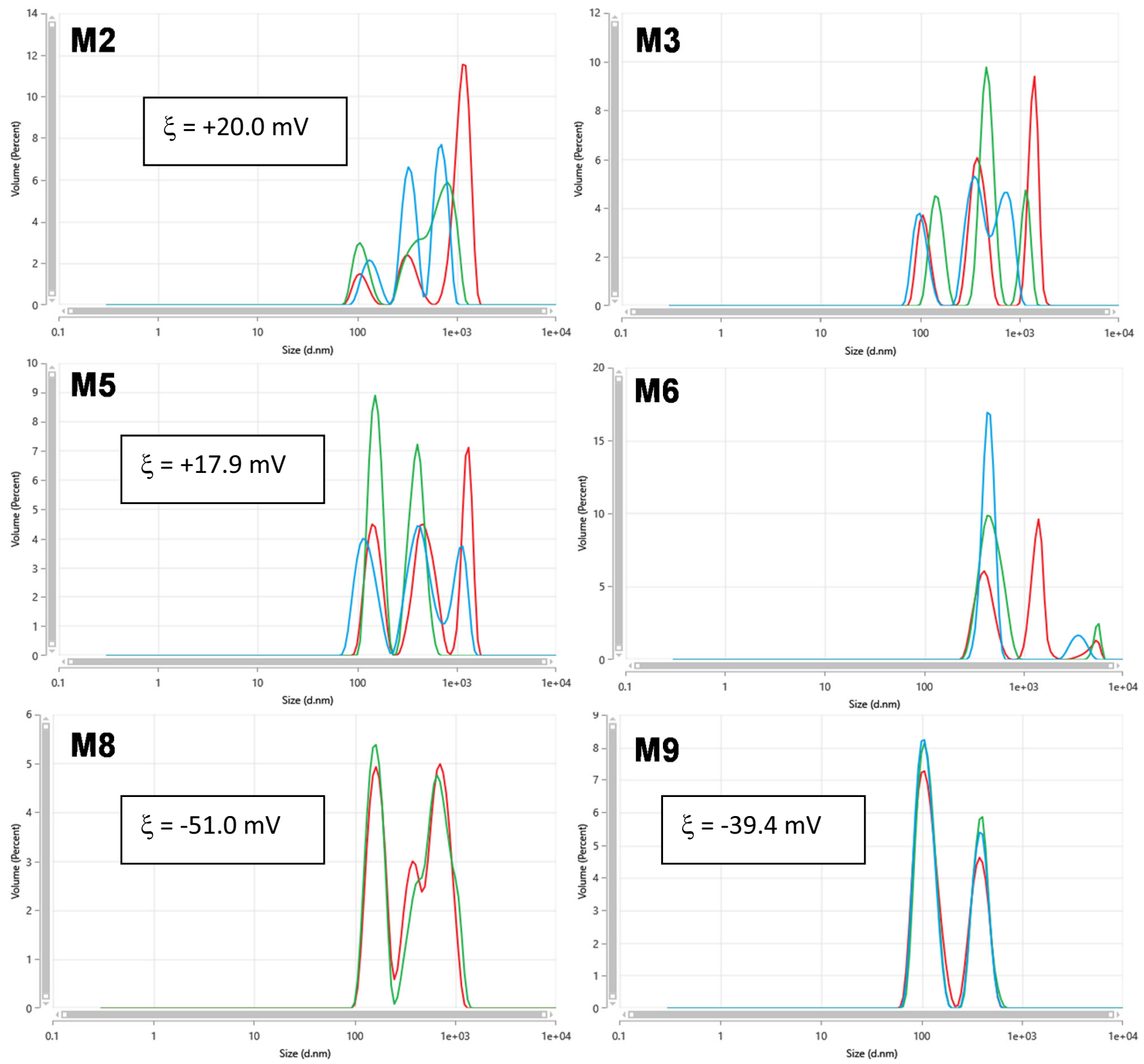

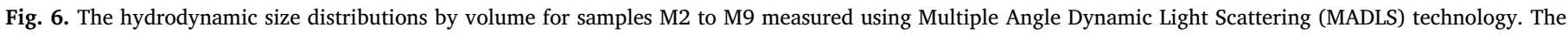
abundances of resolved size populations are given in Table 1 . The results of zeta potential $(\xi)$ measurements are given in the insets and in Table 1 .

degradation of MB. Kuan et al. [46] attributed the oxidation of MB at acidic $\mathrm{pH}$ to the $\mathrm{N}$-demethylation of $\mathrm{MB}$ monomer and H-type aggregation of MB. The color of the MB solution turned less intense during the gradual degradation of the auxochromic alkylamine groups (methyl or methylamine). The decolorization of MB proceeded slowly and noncompletely in the presence of DEAE-dextran (samples M2 to M6). The radiolytically synthesized samples M8 and M9 in the absence of DEAEdextran rapidly and completely decolorize MB (Fig. 7e and f). It can be concluded that DEAE-dextran impairs the adsorption of MB molecules on the particle surface and consequently inhibits the decolorization. This is corroborated by the fact that sample M9 has more than ten times greater BET surface area than samples M3 and M6 that were synthesized in the presence of DEAE-dextran. In addition to the high surface areas the presence of both $\mathrm{Mn}^{2+}$ and $\mathrm{Mn}^{3+}$ in the manganese oxide NPs can contribute to the high decolorization of MB. Debnath et al. [47] demonstrated the superior catalytic activity of $\mathrm{Mn}_{3} \mathrm{O}_{4}$ for degradation of MB compared to that of other Mn-oxide. The activities of $\alpha-\mathrm{Mn}_{2} \mathrm{O}_{3}$ and $\delta-\mathrm{MnO}_{2} \mathrm{NPs}$ were found to be lower in the absence of $\mathrm{Mn}^{2+}$. The presence of both di- and tri- valent manganese was found to be crucial for efficient adsorption/desorption of intermediates that promote faster kinetics for MB degradation.

The results of MB decolorization in the presence of $\mathrm{H}_{2} \mathrm{O}_{2}$ and sample M9 show that the intensity of UV absorption peaks at 615 and $663 \mathrm{~nm}$ gradually decreases without shifting to the lower wavelengths thus suggesting the catalytic degradation of MB (Fig. S5 in the Supplementary Material).

\section{Conclusions}

The manganese oxide nanoparticles were radiolytically synthesized in the presence or absence of DEAE-dextran starting from deoxygenated potassium permanganate $\left(\mathrm{KMnO}_{4}\right)$ alkaline aqueous suspensions.

The samples synthesized in the presence of DEAE-dextran were of low crystallinity, the BET specific areas were low, and their ability to decolorize MB dye was relatively low.

The radiolytically synthesized samples in the absence of DEAEdextran showed high BET specific surface areas, the zeta potential was between -40 and $-50 \mathrm{mV}$, particles were well suspended in aqueous 

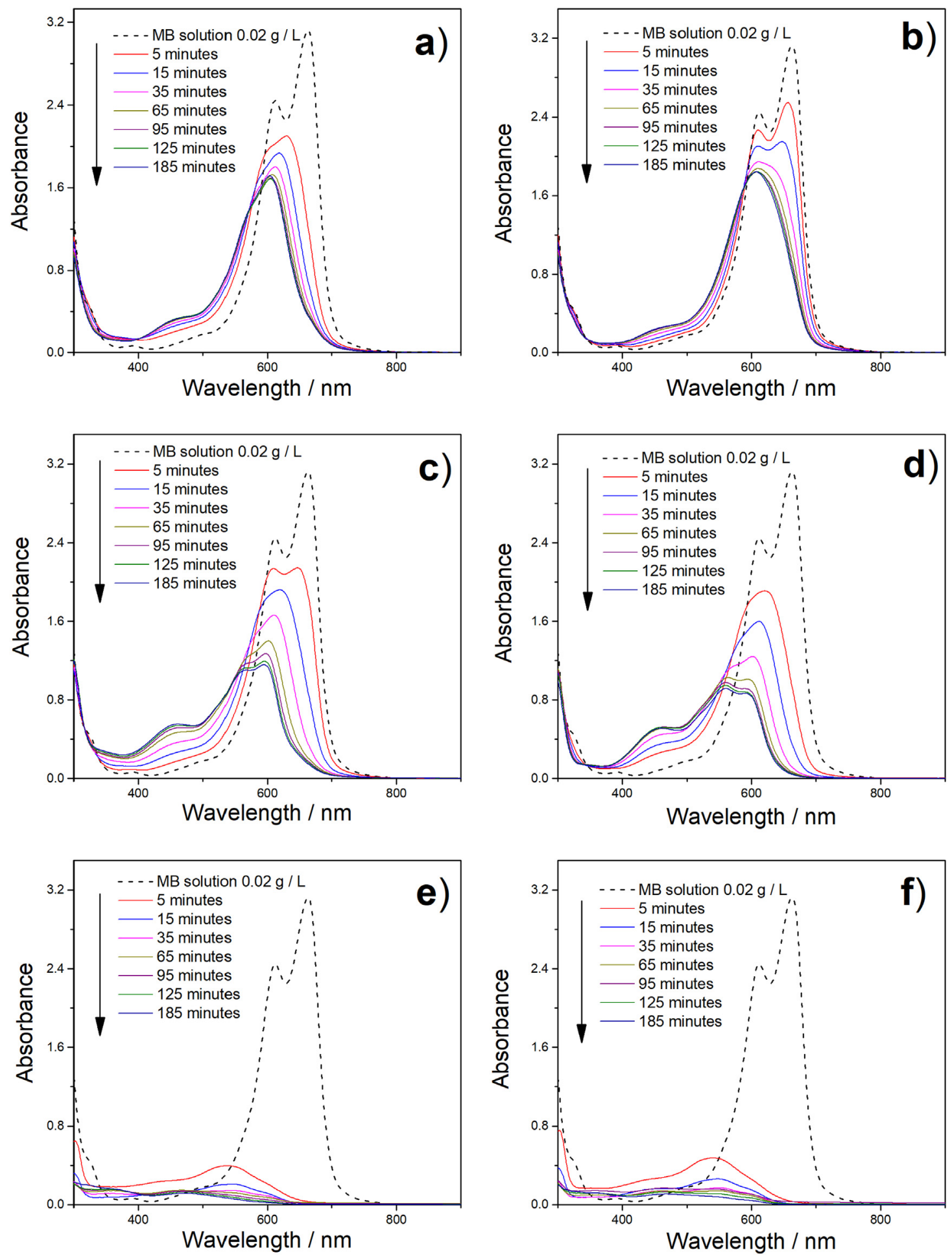

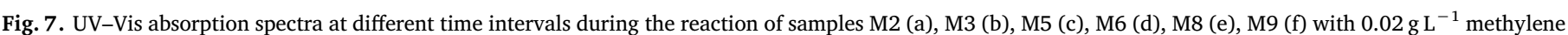

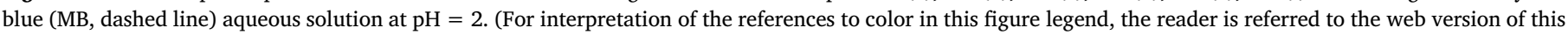
article.)

solutions and showed the highest ability for MB decolorization.

\section{Acknowledgment}

This work has been fully supported by a project co-financed by the "Croatian Government and the European Union through the European Regional Development Fund - the Competitiveness and Cohesion Operational Programme (KK.01.1.1.01.0001)." We thank Mr. Jasmin
Forić for the help in experimental work.

\section{Appendix A. Supplementary data}

Supplementary data to this article can be found online at https:// doi.org/10.1016/j.apsusc.2019.01.212. 


\section{References}

[1] X. Zhang, Z. Xing, Y. Yu, Q. Li, K. Tang, T. Huang, Y. Zhu, Y. Qian, D. Chen, Synthesis of $\mathrm{Mn} 3 \mathrm{O} 4$ nanowires and their transformation to LiMn2O4 polyhedrons, application of LiMn2O4 as a cathode in a lithium-ion battery, CrystEngComm 14 (2012) 1485-1489, https://doi.org/10.1039/C1CE06289A.

[2] R. Ma, Y. Bando, L. Zhang, T. Sasaki, Layered MnO2 nanobelts: hydrothermal synthesis and electrochemical measurements, Adv. Mater. 16 (2004) 918-922, https://doi.org/10.1002/adma.200306592.

[3] D.P. Dubal, D.S. Dhawale, R.R. Salunkhe, S.M. Pawar, C.D. Lokhande, A novel chemical synthesis and characterization of $\mathrm{Mn} 3 \mathrm{O} 4$ thin films for supercapacito application, Appl. Surf. Sci. 256 (2010) 4411-4416, https://doi.org/10.1016/j. apsusc.2009.12.057.

[4] S.-Y. Liu, J. Xie, Y.-X. Zheng, G.-S. Cao, T.-J. Zhu, X.-B. Zhao, Nanocrystal manganese oxide (Mn3O4, MnO) anchored on graphite nanosheet with improved electrochemical Li-storage properties, Electrochim. Acta 66 (2012) 271-278, https://doi.org/10.1016/j.electacta.2012.01.094.

[5] E.R. Stobbe, B.A. de Boer, J.W. Geus, The reduction and oxidation behaviour of manganese oxides, Catal. Today 47 (1999) 161-167, https://doi.org/10.1016/ S0920-5861(98)00296-X.

[6] S. Dey, G.C. Dhal, D. Mohan, R. Prasad, Low-temperature complete oxidation of CO over various manganese oxide catalysts, Atmos. Pollut. Res. 9 (2018) 755-763, https://doi.org/10.1016/j.apr.2018.01.020.

[7] V.P. Santos, M.F.R. Pereira, J.J.M. Órfão, J.L. Figueiredo, The role of lattice oxygen on the activity of manganese oxides towards the oxidation of volatile organic compounds, Appl. Catal. B Environ. 99 (2010) 353-363, https://doi.org/10.1016/j. apcatb.2010.07.007.

[8] H. Masoumbeigi, A. Rezaee, Removal of Methylene Blue (MB) Dye From Synthetic Wastewater Using UV/H2O2 Advanced Oxidation Process, 2, (2015), pp. 160-166.

[9] G. Lu, M. Nagbanshi, N. Goldau, M. Mendes Jorge, P. Meissner, A. Jahn,

F.P. Mockenhaupt, O. Müller, Efficacy and safety of methylene blue in the treatment of malaria: a systematic review, BMC Med. 16 (2018) 59, https://doi.org/10.1186/ s12916-018-1045-3.

[10] J.D. Huber, F. Parker, G.F. Odland, A. Basic Fuchsin, Alkalinized methylene blue rapid stain for epoxyembedded tissue, Stain. Technol. 43 (1968) 83-87, https://doi. org/10.3109/10520296809115048.

[11] P.K. Gillman, CNS toxicity involving methylene blue: the exemplar for understanding and predicting drug interactions that precipitate serotonin toxicity, J. Psychopharmacol. 25 (2011) 429-436, https://doi.org/10.1177/ 0269881109359098.

[12] R. Karthik, R. Muthezhilan, A. Jaffar Hussain, K. Ramalingam, V. Rekha, Effective removal of methylene blue dye from water using three different low-cost adsorbents, Desalin. Water Treat. 57 (2016) 10626-10631, https://doi.org/10.1080/ 19443994.2015.1039598.

[13] J.P.S.D. Pontes, P.R.F. da Costa, D.R. da Silva, S.G. Segura, C.A. Martínez-Huitle, Methylene blue decolorization and mineralization by means of electrochemical technology at pre-pilot plant scale: role of the electrode material and oxidants, Int. J. Electrochem. Sci. 11 (2016) 4878-4891, https://doi.org/10.20964/2016.06.2.

[14] W. Wang, Y. Zhao, H. Bai, T. Zhang, V. Ibarra-Galvan, S. Song, Methylene blue removal from water using the hydrogel beads of poly(vinyl alcohol)-sodium alginate-chitosan-montmorillonite, Carbohydr. Polym. 198 (2018) 518-528, https:// doi.org/10.1016/J.CARBPOL.2018.06.124.

[15] X. Wang, Y. Li, Selected-control hydrothermal synthesis of $\alpha$ - and $\beta$-MnO2 single crystal nanowires, J. Am. Chem. Soc. 124 (2002) 2880-2881, https://doi.org/10. 1021/ja0177105.

[16] Y.-X. Miao, L.-H. Ren, L. Shi, W.-C. Li, Hydrothermal synthesis of manganese oxide nanorods as a highly active support for gold nanoparticles in CO oxidation and their stability at low temperature, RSC Adv. 5 (2015) 62732-62738, https://doi.org/10. 1039/C5RA12182E.

[17] G. Qiu, H. Huang, S. Dharmarathna, E. Benbow, L. Stafford, S.L. Suib, Hydrothermal synthesis of manganese oxide nanomaterials and their catalytic and electrochemical properties, Chem. Mater. 23 (2011) 3892-3901, https://doi.org/10.1021/ cm2011692.

[18] S. Bach, M. Henry, N. Baffier, J. Livage, Sol-gel synthesis of manganese oxides, J. Solid State Chem. 88 (1990) 325-333, https://doi.org/10.1016/0022-4596(90) 90228-P.

[19] A. Sarkar, A. Kumar Satpati, V. Kumar, S. Kumar, Sol-gel synthesis of manganese oxide films and their predominant electrochemical properties, Electrochim. Acta 167 (2015) 126-131, https://doi.org/10.1016/j.electacta.2015.03.172.

[20] N. Amdouni, F. Gendron, A. Mauger, H. Zarrouk, C.M. Julien, LiMn2-yCoyO4 $(0 \leq \mathrm{y} \leq 1)$ intercalation compounds synthesized from wet-chemical route, Mater. Sci. Eng. B 129 (2006) 64-75, https://doi.org/10.1016/j.mseb.2005.12.031.

[21] S.L. Brock, N. Duan, Z.R. Tian, O. Giraldo, H. Zhou, S.L. Suib, A review of porous manganese oxide materials, Chem. Mater. 10 (1998) 2619-2628, https://doi.org/ 10.1021/cm980227h.

[22] D. Yang, Pulsed laser deposition of manganese oxide thin films for supercapacitor applications, J. Power Sources 196 (2011) 8843-8849, https://doi.org/10.1016/j. jpowsour.2011.06.045.
[23] H. Xia, Y. Wan, F. Yan, L. Lu, Manganese oxide thin films prepared by pulsed laser deposition for thin film microbatteries, Mater. Chem. Phys. 143 (2014) 720-727, https://doi.org/10.1016/j.matchemphys.2013.10.005.

[24] K.A.M. Ahmed, Exploitation of $\mathrm{KMnO} 4$ material as precursors for the fabrication of manganese oxide nanomaterials, J. Taibah Univ. Sci. 10 (2016) 412-429, https:// doi.org/10.1016/j.jtusci.2015.06.005.

[25] A.I. Ivanets, V.G. Prozorovich, Y.I. Ryabkov, P.V. Krivoshapkin, L.L. Katsoshvili, Synthesis of manganese oxide sols by $\mathrm{KMnO} 4$ reduction with polyvinyl alcohol in an aqueous medium, Russ. J. Gen. Chem. 87 (2017) 679-683, https://doi.org/10. 1134/s107036321704003x.

[26] P. Ragupathy, H.N. Vasan, N. Munichandraiah, Synthesis and characterization of nano-MnO2 for electrochemical supercapacitor studies, J. Electrochem. Soc. 155 (2008) A34-A40, https://doi.org/10.1149/1.2800163.

[27] M. Gotić, T. Jurkin, S. Musić, K. Unfried, U. Sydlik, A. Bauer-Šegvić, Microstructural characterizations of different Mn-oxide nanoparticles used as models in toxicity studies, J. Mol. Struct. 1044 (2013) 248-254, https://doi.org/10.1016/j.molstruc. 2012.09.083.

[28] M. Gotić, S. Ivanković, S. Musić, T. Prebeg, Synthesis of Mn3O4 nanoparticles and their application to cancer cells, Collect. Czechoslov. Chem. Commun. 74 (2009) 1351-1360, https://doi.org/10.1135/cccc2009047.

[29] N. Hanžić, T. Jurkin, A. Maksimović, M. Gotić, The synthesis of gold nanoparticles by a citrate-radiolytical method, Radiat. Phys. Chem. 106 (2015) 77-82, https:// doi.org/10.1016/J.RADPHYSCHEM.2014.07.006.

[30] T. Jurkin, M. Guliš, G. Dražić, M. Gotić, Synthesis of gold nanoparticles under highly oxidizing conditions, Gold Bull. 49 (2016) 21-33, https://doi.org/10.1007/ s13404-016-0179-3.

[31] N. Hanžić, A. Horvat, J. Bibić, K. Unfried, T. Jurkin, G. Dražić, I. Marijanović, N. Slade, M. Gotić, Syntheses of gold nanoparticles and their impact on the cell cycle in breast cancer cells subjected to megavoltage X-ray irradiation, Mater. Sci. Eng. C Mater. Biol. Appl. 91 (2018) 486-495, https://doi.org/10.1016/j.msec. 2018.05.066.

[32] L. Mikac, T. Jurkin, G. Štefanić, M. Ivanda, M. Gotić, Synthesis of silver nanoparticles in the presence of diethylaminoethyl-dextran hydrochloride polymer and their SERS activity, J. Nanopart. Res. 19 (2017) 299, https://doi.org/10.1007/ s11051-017-3989-1.

[33] M. Gotić, T. Jurkin, S. Musić, Factors that may influence the micro-emulsion synthesis of nanosize magnetite particles, Colloid Polym. Sci. 285 (2007) 793-800, https://doi.org/10.1007/s00396-006-1624-2.

[34] M. Gotić, T. Jurkin, S. Musić, From iron(III) precursor to magnetite and vice versa, Mater. Res. Bull. 44 (2009) 2014-2021, https://doi.org/10.1016/j.materresbull. 2009.06.002.

[35] T. Jurkin, K. Zadro, M. Gotić, S. Musić, Investigation of solid phase upon $\gamma$-irradiation of ferrihydrite-ethanol suspension, Radiat. Phys. Chem. 80 (2011) 792-798, https://doi.org/10.1016/J.RADPHYSCHEM.2011.02.031.

[36] T. Jurkin, G. Štefanić, G. Dražić, Synthesis route to $\delta$-FeOOH nanodiscs, Mater. Lett. 173 (2016) 55-59, https://doi.org/10.1016/j.matlet.2016.03.009.

[37] T. Jurkin, M. Gotić, G. Štefanić, I. Pucić, Gamma-irradiation synthesis of iron oxide nanoparticles in the presence of PEO, PVP or CTAB, Radiat. Phys. Chem. 124 (2016) 75-83, https://doi.org/10.1016/J.RADPHYSCHEM.2015.11.019.

[38] C. Lume-Pereira, S. Baral, A. Henglein, E. Janata, Chemistry of colloidal manganese dioxide. 1. Mechanism of reduction by an organic radical (a radiation chemical study), J. Phys. Chem. 89 (1985) 5772-5778, https://doi.org/10.1021 j100272a040.

[39] Y. Liu, Y. Qian, Y. Zhang, M. Zhang, Z. Chen, L. Yang, C. Wang, Z. Chen, Preparation of nanocrystalline manganic oxide $\mathrm{Mn} 2 \mathrm{O} 3$ powders by use of $\gamma$-ray radiation, Mater. Lett. 28 (1996) 357-359, https://doi.org/10.1016/0167-577X(96)00086-9.

[40] Y.P. Liu, Y.T. Qian, Y.H. Zhang, M.W. Zhang, C.S. Wang, L. Yang, $\gamma$-Ray radiation preparation and characterization of nanocrystalline manganese dioxide, Mater. Res. Bull. 32 (1997) 1055-1062, https://doi.org/10.1016/S0025-5408(97)00069-X.

[41] Y. Hu, J. Chen, X. Xue, T. Li, Synthesis of monodispersed single-crystal compassshaped Mn3O4 via gamma-ray irradiation, Mater. Lett. 60 (2006) 383-385, https:// doi.org/10.1016/j.matlet.2005.08.056.

[42] G. Williamson, W. Hall, X-ray line broadening from filed aluminium and wolfram, Acta Metall. 1 (1953) 22-31, https://doi.org/10.1016/0001-6160(53)90006-6.

[43] D.L. Bish, J.E. Post, Modern Powder Diffraction, The Mineralogical Society of America, Washington, D. C, 1989.

[44] G. Štefanić, S. Krehula, I. Štefanić, Phase development during high-energy ballmilling of zinc oxide and iron - the impact of grain size on the source and the degree of contamination, Dalton Trans. 44 (2015) 18870-18881, https://doi.org/10.1039/ C5DT02498F.

[45] H.C.B. Hansen, Composition, stabilization, and light absorption of Fe(II)Fe(III) hydroxy-carbonate ('green rust'), Clay Miner. 24 (1989) 663-669, https://doi.org/ 10.1180/claymin.1989.024.4.08

[46] W.H. Kuan, C.Y. Chen, C.Y. Hu, Removal of methylene blue from water by $\gamma-\mathrm{MnO} 2$, Water Sci. Technol. 64 (2011) 899-903, https://doi.org/10.2166/wst.2011.262.

[47] B. Debnath, A.S. Roy, S. Kapri, S. Bhattacharyya, Efficient dye degradation catalyzed by manganese oxide nanoparticles and the role of cation valence, ChemistrySelect 1 (2016) 4265-4273, https://doi.org/10.1002/slct.201600806. 